\title{
Evidence for Proteotoxicity in $\beta$ Cells in Type 2 Diabetes
}

\section{Toxic Islet Amyloid Polypeptide Oligomers Form Intracellularly in the Secretory Pathway}

\author{
Tatyana Gurlo, ${ }^{*}$ Sergey Ryazantsev, ${ }^{\dagger}$ \\ Chang-jiang Huang, ${ }^{*}$ Michael W. Yeh, ${ }^{\ddagger}$ \\ Howard A. Reber, ${ }^{\S}$ O. Joe Hines,,$^{\S}$ \\ Timothy D. O'Brien, " Charles G. Glabe," \\ and Peter C. Butler*

\begin{abstract}
From the Larry Hillblom Islet Research Center," the Department of Surgery, Endocrine Surgical Unit, and the Department of Surgery, ${ }^{\varsigma}$ David Geffen School of Medicine, University of California, Los Angeles, California; the Electron Imaging Center for Nanomachines, ${ }^{\dagger}$ California Nano Systems Institute, University of California, Los Angeles, California; the Veterinary Population Medicine Department, ${ }^{\pi}$ University of Minnesota, St. Paul, Minnesota; and the Department of Molecular Biology and Biochemistry," University of California, Irvine, California
\end{abstract}

The islet in type 2 diabetes mellitus (T2DM) is characterized by a deficit in $\boldsymbol{\beta}$ cells and islet amyloid derived from islet amyloid polypeptide (IAPP), a protein coexpressed with insulin by $\beta$ cells. It is increasingly appreciated that the toxic form of amyloidogenic proteins is not amyloid but smaller membrane-permeant oligomers. Using an antibody specific for toxic oligomers and cryo-immunogold labeling in human IAPP transgenic mice, human insulinoma and pancreas from humans with and without T2DM, we sought to establish the abundance and sites of formation of IAPP toxic oligomers. We conclude that IAPP toxic oligomers are formed intracellularly within the secretory pathway in T2DM. Most striking, IAPP toxic oligomers appear to disrupt membranes of the secretory pathway, and then when adjacent to mitochondria, disrupt mitochondrial membranes. Toxic oligomer-induced secretory pathway and mitochondrial membrane disruption is a novel mechanism to account for cellular dysfunction and apoptosis in T2DM. (Am J Pathol 2010, 176:861-869; DOI: 10.2353/ajpath.2010.090532)
Type 2 diabetes (T2DM) is characterized by a progressive deficit in $\beta$ cell function and mass with increased $\beta$ cell apoptosis. ${ }^{1,2}$ In common with several neurodegenerative diseases such as Alzheimer's disease, Parkinson's disease, and Huntington's disease, the loss of $\beta$ cells in T2DM is associated with accumulation of locally expressed misfolded proteins that share a propensity to form amyloid. ${ }^{3}$ Islet amyloid in T2DM is composed primarily of a 37-amino acid protein, islet amyloid polypeptide (IAPP). ${ }^{3}$ IAPP is co-expressed and secreted with insulin by pancreatic $\beta$ cells, and is thought to play a paracrine inhibitory role in regulation of insulin secretion. ${ }^{4,5}$ The property of IAPP to form amyloid fibrils depends on IAPP $_{20-29}$. This sequence is closely homologous in humans, nonhuman primates and cats, ${ }^{6}$ all of which spontaneously develop T2DM characterized by a deficit in $\beta$ cell mass and islet amyloid. In contrast, rodent IAPP (mouse and rat) does not have the propensity to form amyloid fibrils due to proline substitutions in APP $_{20-29}$ and wild-type mice and rats do not spontaneously develop T2DM.

There is accumulating evidence that the toxic form of amyloidogenic protein aggregates is distinct from amyloid fibrils. The latter tend to accumulate extracellularly where they are relatively inert. ${ }^{3,7}$ Abnormal non-fibrillar intracellular IAPP aggregates were noted in human insulinoma tissue adjacent to disrupted intracellular membranes. ${ }^{8}$ The impression that IAPP oligomers might act by disruption of cell membranes was supported by the observation that oligomers of IAPP, like Alzheimer $\beta$ pro-

\footnotetext{
Supported by grants from the National Institutes of Health (DK059579) and the Larry L. Hillblom Foundation (2007-D-003-NET).

Accepted for publication October 20, 2009.

Supplemental material for this article can be found on http://ajp. amjpathol.org.

Address reprint requests to Peter C. Butler, M.D., Larry Hillblom Islet Research Center, David Geffen School of Medicine, UCLA, 900 Veteran Avenue, 24-130 Warren Hall, Los Angeles, CA 90095-7073. E-mail: pbutler@mednet.ucla.edu.
} 
tein $\left(A \beta P_{1-42}\right)$, can act as nonselective ion channels and disrupt membranes. ${ }^{7,9}$ Moreover toxic oligomers formed from different amyloidogenic proteins apparently share a close structure. This was revealed by the finding that antibodies raised against toxic oligomers of $A \beta P_{1-42}$ also bind to those formed from IAPP, synuclein, and prion, in each case neutralizing the toxicity of these oligomers. ${ }^{10}$ Availability of this antibody provided an important tool to resolve the question, do toxic oligomers form intra or extracellularly?

To test the hypothesis that IAPP oligomers form and act intracellularly requires ultrastructural studies. This presents challenges since the antibody for toxic oligomers loses specificity and sensitivity with many fixation and tissue embedding procedures used for conventional electron microscopy. To overcome this, we used cryoimmunogold labeling by oligomer-specific antibody in islets isolated from human IAPP (hIAPP) transgenic mice. The hypothesis that toxic oligomers form intracellularly was confirmed, with toxic IAPP oligomers present in $\beta$ cells at all steps of the secretory pathway. These findings were reproduced in IAPP expressing human insulinoma, supporting the concept that IAPP oligomers form in the secretory pathway in humans. Finally, toxic oligomers were also identified intracellularly in $\beta$ cells in humans with T2DM.

\section{Materials and Methods}

\section{Design}

Using an anti-toxic oligomer antibody ${ }^{10}$ abbreviated to A11, we previously detected toxic oligomers by light microscopy in $\beta$ cells of hIAPP, but not rat IAPP (rIAPP) transgenic mice. ${ }^{11}$ In those studies we noted that $A 11$ antibody loses specificity and sensitivity with routine formaldehyde fixation and tissue processing. We established that $A 11$ retained sensitivity and specificity to detect IAPP oligomers in frozen tissue after mild fixation, but not in paraffin-embedded tissue. For this reason regular tissue fixation and embedding in plastic for electron microscopy was not suitable for oligomer detection. Therefore, we used cryo-immunogold labeling in the present studies to identify the ultrastructural distribution of toxic oligomers. The requirement for cryopreservation decreases availability of tissue from humans. Freshly procured human pancreatic tissue suitable for the required immediate fixation/freezing protocol is limited to surgical specimen.

We therefore chose to first establish the intracellular location of IAPP toxic oligomers in pancreatic $\beta$ cells from hIAPP versus rIAPP transgenic mice. IAPP amyloid is present in some insulinomas implying protein misfolding, as well as in islets of humans with T2DM. We therefore also studied IAPP expressing human insulinoma and pancreas from humans with and without T2DM obtained at surgery.

\section{Human and Rodent IAPP Transgenic Mouse Models}

Development and characterization of transgenic mice homozygous for human IAPP (hIAPP: FVB-Tg(IAPP)6Jdm/
Tg(IAPP)6Jdm) and rodent IAPP (rlAPP: FVB/N-Tg(lapp) 6 Wcs/Tg(lapp)6Wcs) have been described elsewhere. ${ }^{12}$ Control wild-type FVB mice (wild-type) were purchased from Charles Rivers Laboratory (Wilmington, MA). Animal studies were approved by the University of California at Los Angeles Animal Research Committee. Male mice were used for the experiments. Fasting blood glucose concentrations and body weight on the day of sample collection are presented in Supplemental Table S1 (http:// ajp.amjpathol.org.).

\section{Islet Preparation}

Mouse islets were prepared by collagenase digestion as described ${ }^{12}$ with some modifications. After overnight fast mice were euthanized using isoflurane. The bile duct was clamped at the entrance to duodenum, cannulated, and pancreas was perfused with $2 \mathrm{ml}$ of collagenase solution [HBSS (Invitrogen, Carlsbad, CA) supplemented with 25 mmol/L HEPES (Invitrogen), 0.23 mg/ml liberase (Roche, Penzberg, Germany), and $0.1 \mathrm{mg} / \mathrm{ml}$ DNase (Roche)]. Pancreas was removed, transferred into a glass vial containing $2 \mathrm{ml}$ of ice-cold collagenase solution (2 pancreata per vial), digested for 19 minutes at $37^{\circ} \mathrm{C}$, then dispersed by shaking for 30 seconds. The suspension was transferred into $30 \mathrm{ml}$ of ice cold $4 \%$ formaldehyde in PBS, $\mathrm{pH}$ 7.4 to 7.6, (formaldehyde from Polysciences, Warrington, PA). After 5 minutes incubation on ice, 3/4 of supernatant was removed by aspiration, and fresh ice-cold fixative was added to the pellet. Fixative change was done one more time; then islets were manually picked and transferred into fresh ice-cold fixative. After 8 hours of fixation, islets were embedded in low melting point agarose (Ultra Pure from Invitrogen, Carlsbad, CA).

\section{Human Tissue}

Cases studied are summarized in Supplemental Table S2 (http://ajp.amjpathol.org). Surgically removed human tissue specimens were obtained in accordance with University of California at Los Angeles Institutional Review Board approval. For insulinoma evaluation a slice of insulinoma tumor tissue was provided. For evaluation of pancreatic islets in T2DM versus nondiabetic controls, a slice of tumor-free pancreas was procured. Immediately after resection, a thin slice of tissue was placed into ice-cold fixative ( $4 \%$ formaldehyde $+0.1 \%$ glutaraldehyde in PBS), cut into $\sim 1 \mathrm{~mm}^{3}$ cubes, transferred into a new portion of fixative, left for 16 hours at $4^{\circ} \mathrm{C}$, then processed for cryo-immunogold labeling as described below. Another slide of the specimen was fixed overnight in $4 \%$ formaldehyde; then half was frozen in optimal cutting temperature compound and half in paraffin for light microscopy.

\section{Antibodies}

For oligomer detection we used two different lots of oligomer-specific $A b(A 11)$ raised as previously described against stable soluble oligomers of $\mathrm{A} \beta \mathrm{P}_{1-40}$ and was well 
characterized. ${ }^{10}$ Other antibodies used included: rabbit anti-human amylin (25-37; Peninsula, San Carlos, CA); mouse anti-human amylin peptide (7-18; clone R10-99, Serotec, Raleigh, NC); guinea-pig anti-insulin (Zymed, San Francisco, CA); and mouse anti-KDEL (clone 10C3, Calbiochem, San Diego, California).

Secondary antibodies for immunofluorescence were $\mathrm{F}\left(\mathrm{ab} \mathrm{b}_{2}\right)_{2}$ conjugates from Jackson Immunoresearch Laboratories (West Grove, PA). Secondary antibodies for cryo-immunogold labeling were the following: goat antirabbit or anti-mouse IgG $F\left(a b^{\prime}\right) 2$ conjugated to 5 or 10 nm gold from Tedd Pella (Redding, CA), donkey antiguinea pig IgG conjugated to $6 \mathrm{~nm}$ from Jackson Immunoresearch.

For subcellular localization of oligomers by electron microscopy we used the same batch of A11 antibody previously shown to be specific for oligomers, but not for amyloid in mice; and confirmed to be protective against toxicity of exogenously added pre-formed IAPP oligomers. ${ }^{11}$ For human immunofluorescence studies we used a new batch of A11 antibody. The second batch of the A11 antibody provided a similar pattern of immunostaining of $\beta$-cells in hIAPP transgenic mice, with no reactivity to islets from wild-type mice or rIAPP transgenic mice, and showed positivity to the in vitro preformed oligomers from human IAPP tested by dot blot (data not shown).

\section{Cryo-Immunogold Labeling}

Islet pellets in agarose (or pancreatic tissue samples) were embedded and sectioned as described. ${ }^{13}$ Sections were incubated with primary antibodies diluted in 20 $\mathrm{mmol} / \mathrm{L} \mathrm{Tris} / 150 \mathrm{mmol} / \mathrm{L} \mathrm{NaCl} / 1 \%$ bovine serum albumin at $4^{\circ} \mathrm{C}$ overnight, washed three times with the same buffer, and then incubated with secondary antibody for 45 minutes at room temperature. After washing, the sections were fixed with $0.8 \%$ glutaraldehyde, and treated with $1 \%$ uranye acetate (UA) in $1.3 \%$ methylcellulose, air-dried. Samples were analyzed within 1 to 3 days after staining using a JEM 1200-EX transmission microscope (JEOL, Japan) equipped with a BioScan 600W digital camera (Gatan, Inc., Pleasanton, CA). Double-staining procedure was performed using mixtures of primary and then secondary antibodies.

\section{Conventional Immunogold Labeling}

Pancreas sample from hIAPP transgenic mouse was fixed in PBS/2\%FA/2\%GA and embedded in Epon. UItrathin sections were placed on nickel grids, etched with $0.1 \%$ sodium borohydride in PBS and stained for IAPP as described for cryo-immunogold labeling, and then treated with saturated uranye acetate and Reynolds lead citrate solution.

\section{Immunofluorescent Staining}

Pancreatic sections were prepared from $4 \%$ formaldehyde-fixed tissue embedded in optimal cutting tempera- ture compound or paraffin after 24 hours' fixation, and stained as described. ${ }^{11}$

\section{Image Analysis \\ Immunofluorescence}

All islets on the section were imaged using a Leica DM6000 microscope with $\times 20$ objective. One to three sections per case were analyzed. The number of $\beta$ cells analyzed for each case is listed in Supplemental Table S2 (http://ajp.amjpathol.org).

\section{Electron Microscopy}

Random images of $\beta$ cells in rodent islets were taken at magnification $\times 6000$ to $\times 10,000$, then 5 to 10 images of the same cell were obtained at magnification $\times 60,000$ to $\times 120,000$, in average 40 to 80 areas per grid were analyzed. For hIAPP transgenic mice a total of 450 images were analyzed ( $\sim 90$ per experiment, two independent islet preparations), for rIAPP transgenic mice a total 130 images were analyzed ( $\sim 45$ per experiment, three independent islet preparations), for wild-type mice a total 75 images were analyzed (single experiment, two grids). For quantitative analysis of the intensity of oligomer staining single antibody stained grids (A11, $10 \mathrm{~nm}$ gold particles) were analyzed.

\section{Results}

Transgenic Overexpression of Human but Not Rat IAPP in Mice Leads to Intracellular Formation of Toxic IAPP Oligomers within the Secretory Pathway

\section{Oligomers Are Present in ER and Golgi}

Immunoreactivity for toxic oligomers (cryo-immunogold lableling) was intracellular, in some but not all $\beta$ cells of hIAPP transgenic mice. Toxic oligomers were associated with endoplasmic reticulum (ER) membranes in the perinuclear region (Figure $1 \mathrm{~A}$ ) as well as in the peripheral ER cisternae (Figure 1B) in hIAPP transgenic mice. Toxic oligomer immunoreactivity was most obvious in association with distended areas of ER present as projections into the distended ER lumen. Occasional areas of immunoreactivity were also present in Golgi of $\beta$ cells from hIAPP but not rIAPP transgenic mice (Figure 1, C and D).

\section{Oligomers Are Present in the Secretory Vesicles and Cytosol from Apparently Disrupted Vesicles}

Toxic oligomer immunoreactivity was most abundant in insulin secretory vesicles in hIAPP transgenic mice (Figure 2, $\mathrm{A}$ and $\mathrm{B}$ ). In $\beta$-cells from hIAPP transgenic mice, about $50 \%$ of secretory vesicles had oligomer-specific 


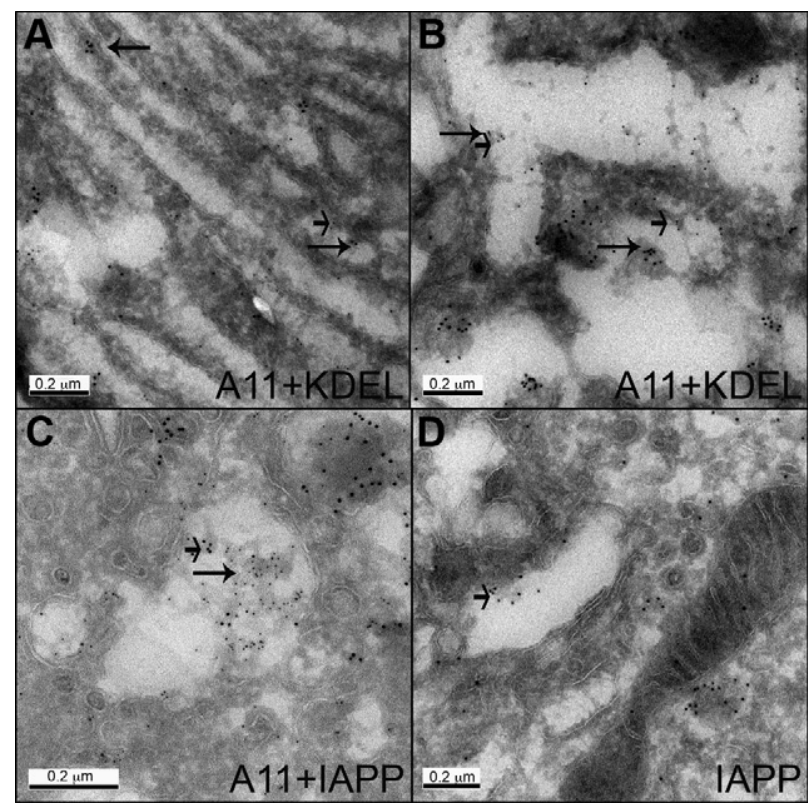

Figure 1. Oligomer-specific immunoreactivity was found in association with the ER membrane and in the distended ER lumen (A, B), and in the Golgi system $(\mathbf{C}, \mathbf{D})$. Sections of islets from hIAPP transgenic mice were labeled for oligomers (A11) and ER marker KDEL (A, B; $10 \mathrm{~nm}$ gold and $5 \mathrm{~nm}$ gold, respectively); co-labeled for oligomers (A11) and IAPP (C, $5 \mathrm{~nm}$ and $10 \mathrm{~nm}$ gold respectively); labeled for IAPP (D; $10 \mathrm{~nm}$ gold). Long arrows point to oligomers, short arrows point to $\operatorname{KDEL}(\mathbf{A}, \mathbf{B})$ or IAPP $(\mathbf{C}, \mathbf{D})$. Original magnification: $\times 100,000(\mathbf{A}, \mathbf{C}, \mathbf{D})$ and $\times 150,000(\mathbf{B})$.

labeling in contrast to $\sim 15 \%$ of vesicles in rIAPP transgenic mice. The intensity of A11 labeling was threefold greater in hIAPP versus rIAPP-positive islets.

Oligomer-specific labeling was present in both mature dense core vesicles and immature vesicles. In addition to vesicles containing a defined membrane, oligomer immunoreactivity was present in cytosol in what appeared to be the former contents of vesicles that had emerged from disrupted vesicle membranes (Figure 2C).

\section{Cytosolic Oligomers Interact with Mitochondria}

A striking finding in hIAPP transgenic mice was disrupted mitochondrial membranes when these were adjacent to the cytosolic foci of oligomers that had apparently escaped from the secretory pathway. In Figure 2, D and E, IAPP-labeled aggregates penetrate adjacent mitochondria that have lost their inner cristae. In contrast, mitochondria remote from the aggregates are relatively normal. For comparison, an intact mitochondrion in close proximity to secretory vesicles in an rIAPP transgenic mouse labeled for IAPP is shown in Figure 2F. This intimate relationship between toxic oligomer immunoreactivity and disruption of mitochondrial membranes, present in hIAPP transgenic mice, but not rIAPP mice, provides a potential novel mechanism for mitochondrial dysfunction in both $\beta$ cells in T2DM and neurodegenerative diseases also characterized by aggregation of amyloidogenic proteins.

Because membranes are less defined in tissue prepared for cryo-immunogold labeling required for A11 detection than conventional electron microscopy, we also

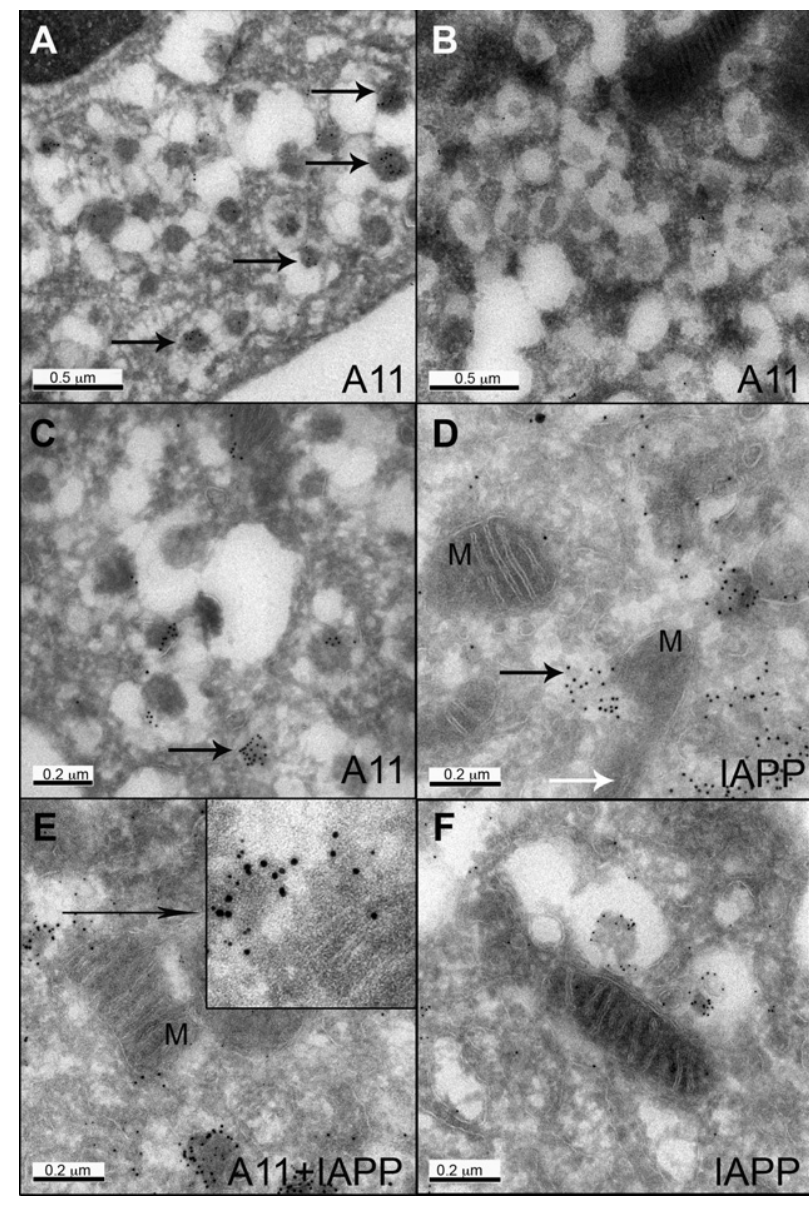

Figure 2. Oligomer immunoreactivity (A11, $10 \mathrm{~nm}$ gold) was found in the secretory vesicles (A, arrows) and diffuse aggregates $(\mathbf{C}$, arrow) in $\beta$ cells from hIAPP transgenic mice, but only occasional weak labeling in $\beta$ cells from rIAPP transgenic mice (B). D, E: IAPP and oligomer labeled aggregates were found adjacent to mitochondria, and mitochondria (M) integrity appeared to be compromised (black arrow points to the aggregates penetrating mitochondria; white arrow points to the remnant of cristae in damaged mitochondria). F: For comparison, despite the presence of an immediately adjacent vesicle labeled for IAPP, the mitochondrion is intact in a $\beta$ cell from a rIAPP transgenic mouse $(5 \mathrm{~nm}$ gold). Original magnification: $\times 60,000$ (A B); $\times 100,000(\mathbf{C}, \mathbf{F}) ; \times 120,000(\mathbf{D}, \mathbf{E})$.

examined $\beta$ cells in hIAPP transgenic mice with conventional immunogold labeling for IAPP (Figure 3). Aggregates of IAPP labeling are present in cytoplasm adjacent to disrupted secretory vesicles (Figure 3A). These were also identified adjacent to ER (Figure 3B) arising from dense core secretory granules. In other areas of distended ER, aggregates of IAPP immunogold labeling were associated with ER membrane that had lost its usual structure (Figure 3, C and D).

\section{Toxic Oligomers Are Also Observed Intracellularly in $\beta$ Cells in Human Insulinoma and Humans with T2DM}

Extracellular islet amyloid derived from IAPP serves as evidence of IAPP misfolding in both human insulinoma tissue and islets in humans with T2DM. Sensitivity and specificity of the A11 antibody for detection of toxic oli- 


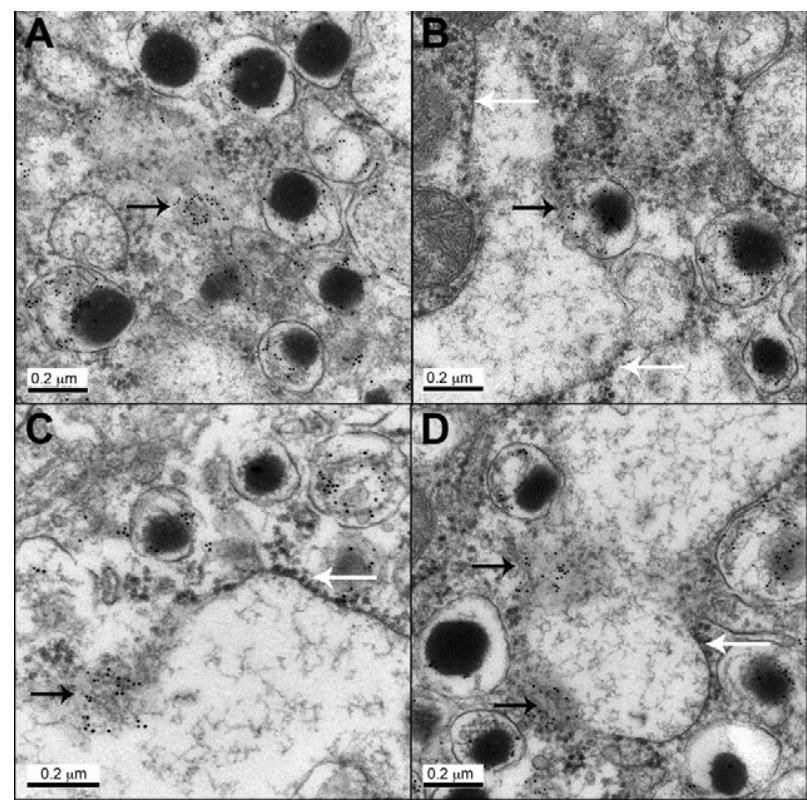

Figure 3. Immunogold labeling for IAPP in $\beta$ cells from hIAPP transgenic mice (regular electron microscopy). A: Immunoreactivity was found in secretory vesicles and diffuse aggregates in the cytoplasm (arrow). B: Secretory vesicle appears to discharge IAPP (black arrows) into the ER lumen. C, D: Diffuse aggregates were found in association with ER membrane that lost its integrity (black arrow). White arrows point to the ribosomes at the ER membrane. Original magnification: $\times 100,000(\mathbf{A}, \mathbf{B}, \mathbf{D})$, and $\times 120,000(\mathbf{C})$.

gomers is lost during conventional fixation and paraffin embedding, being retained only in frozen tissue. For this study we therefore obtained insulinoma and pancreas, removed surgically and rapidly processed for detection of toxic oligomers.

\section{Insulinoma}

IAPP expression detected by light microscopy was present in four of six cases obtained for these studies, consistent with prior studies. ${ }^{8}$ Toxic oligomer immunostaining by immunofluorescent microscopy was confined to the four IAPP-expressing cases (Supplemental Figure 1, http://ajp.amjpathol.org). In common with hIAPP transgenic mice, immunostaining for A11 in human insulinoma was intracellular, the pattern and intensity of staining being heterogeneous between cells.

Cryo-immunogold labeling of oligomers in human insulinoma shared many features of $\beta$ cells from hIAPP transgenic mice (Figure 4). Occasional labeling was detected in Golgi, but was most frequent in secretory vesicles (Figure 4A), the extent of labeling varied between cells. As in mice, we found occasional cytosolic immunoreactivity for oligomers adjacent to mitochondria with compromised integrity of adjacent mitochondrial membranes (Figure 4B). In contrast to hIAPP transgenic mice, in insulinoma cells we also noted numerous membranebound vacuoles with the appearance of autophagosomes with luminal labeling for oligomers (Figure 4, C and D).

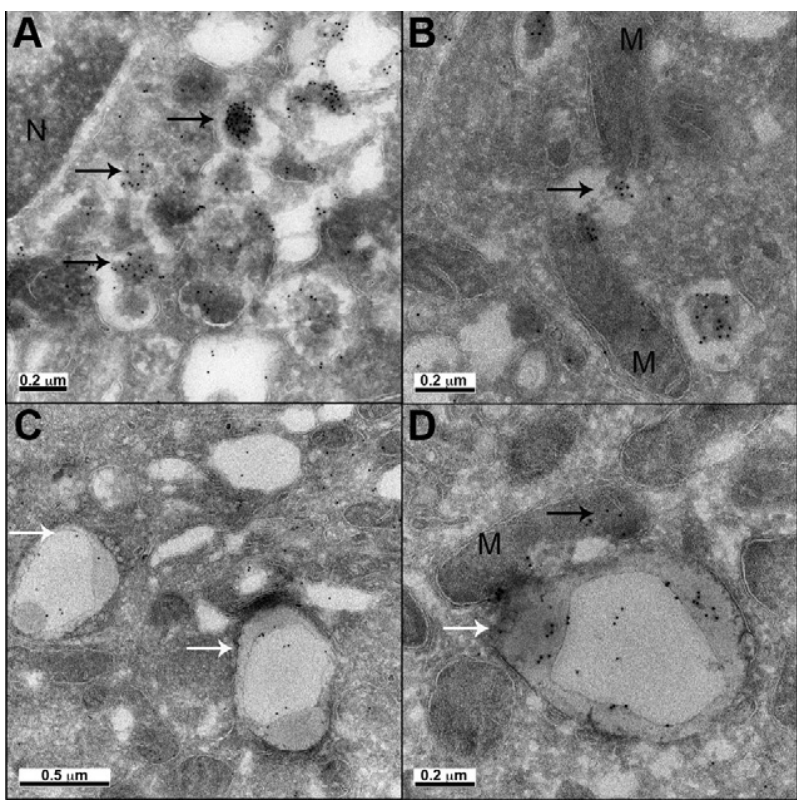

Figure 4. Electron micrographs of human insulinoma cells expressing IAPP A: Oligomer immunoreactivity (10 $\mathrm{nm}$ gold) was detected in perinuclear area in vesicle-like structures and aggregates ( $\mathrm{N}$, nucleus). B: Some oligomer aggregates appear to compromise mitochondria (M) integrity. C, D: Oligomer labeling was detected in vacuoles located in membrane rich areas, which appear to be autophagosomes. Black arrows point to oligomers (A $\mathbf{B}, \mathbf{D})$; white arrows point to autophagosomes $(\mathbf{C}, \mathbf{D})$. Original magnification: $\times 60,000(\mathbf{C}), \times 80,000(\mathbf{A}), \times 100,000(\mathbf{B}, \mathbf{D})$.

\section{IAPP Toxic Oligomers Are Present in Human $\beta$ Cells in T2DM, and More Frequent with Increasing Obesity}

Pancreas tissue was obtained at surgery from 13 patients undergoing pancreatic resection for pancreatic tumors (Supplemental Table S2, http://ajp.amjpathol.org). In pancreas distant from the tumor we detected intracellular oligomer immunoreactivity in $\beta$ cells (Figure 5). Oligomer immunostaining was more abundant in T2DM than in nondiabetic cases, but occasionally also present in nondiabetic cases (Figure 6). Oligomer immunoreactivity increased with obesity in T2DM.

Within $\beta$-cells, oligomer staining was both perinuclear and in small discrete deposits similar to that detected in mouse $\beta$ cells overexpressing human IAPP (Figure 5, A and $\mathrm{B}$ ), or cytoplasmic (Figure $5 \mathrm{C}$ ). Labeled cells were found in adjacent clusters within islets. We also noted lobular distribution of oligomer labeling, with some lobules containing more positive islets than others.

Cryo-immunogold labeling was undertaken in case number 3 with T2DM. Oligomer labeling was identified in this case, and was confined to $\beta$ cells, in aggregates associated with distended areas of ER (Figure 7A), in Golgi stacks and in abnormal aggregates in poorly defined structures (Figure 7B). As in hIAPP transgenic mice, labeling was also present in secretory vesicles (Figure 7C). Occasionally oligomer labeling was present in the intercellular space associated with the plasma membrane (Figure 7D), suggesting that intracellularly formed oligomers can be released from the cells. 


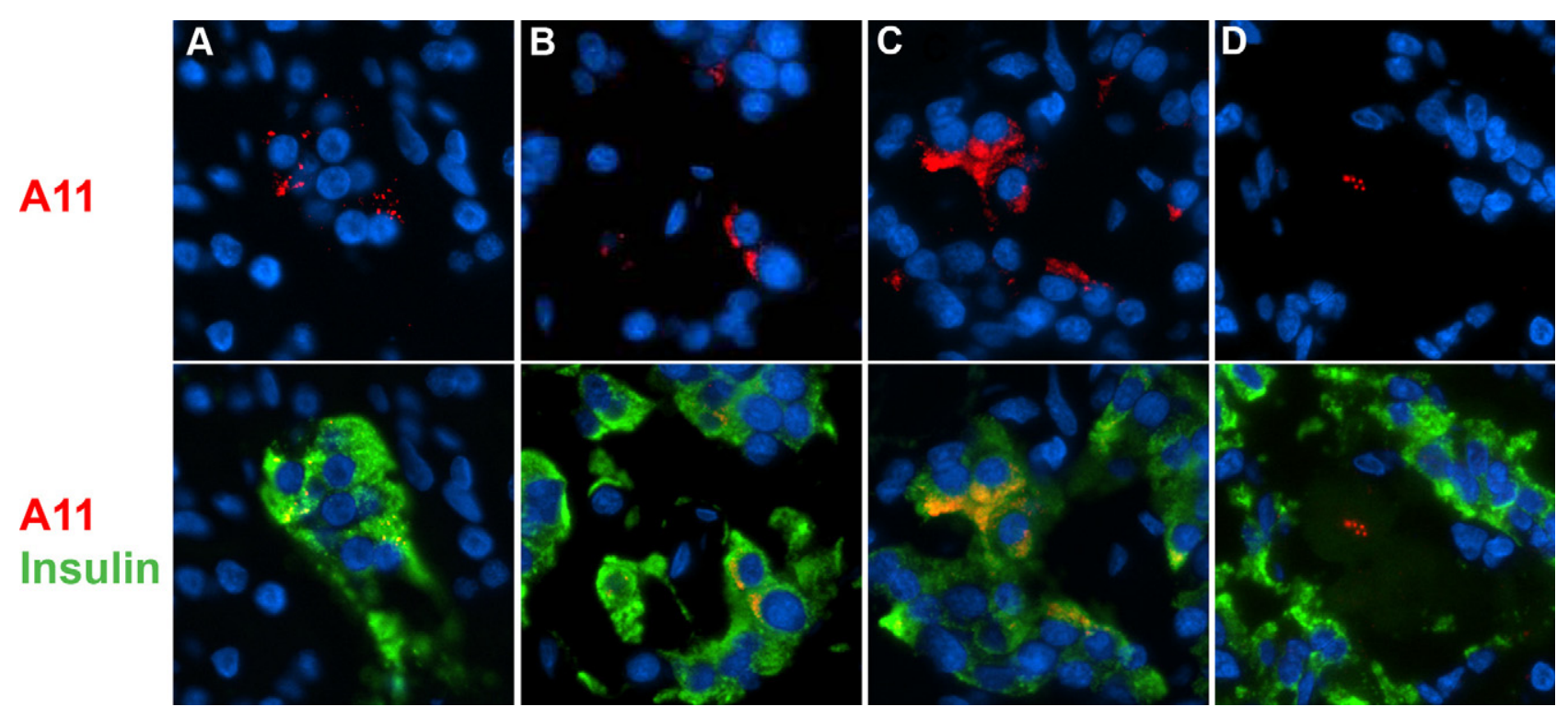

Figure 5. A11 immunoreactivity was detected in $\beta$ cells from T2DM cases in different patterns. A: Spotted (a, image from case \#4). B: Perinuclear (image from case \#2). C: Cytoplasmic (image from insulinoma case with prior T2DM). D: In some occasions, staining was detected inside the amyloid deposits (image from insulinoma case with prior T2DM). Nuclei were visualized with DAPI.

\section{Insulinoma and T2DM}

One case of T2DM of 20 years duration presented a unique opportunity in as much as the patient had developed an insulinoma and had been hypoglycemic for approximately 2 years before surgery (Supplemental Table S2 http://ajp.amjpathol.org). This case of T2DM had minimal oligomer immunoreactivity in $\beta$ cells. In the same case, we detected immunoreactivity in the core of the islet amyloid deposits (Figure 5D).

\section{Discussion}

We report that IAPP toxic oligomers are present more frequently in $\beta$ cells of patients with T2DM, and increase in abundance with obesity. When present, toxic IAPP oligomers are present throughout the secretory pathway

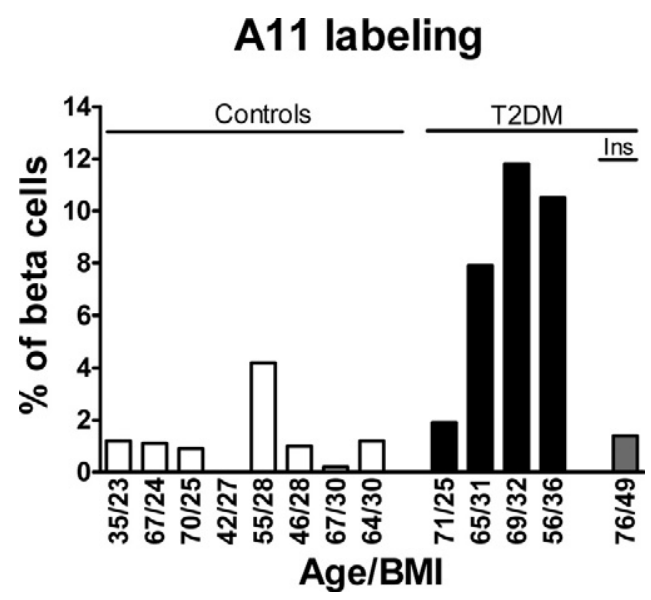

Figure 6. Oligomer labeling in human $\beta$ cells is more frequent in T2DM cases then in controls, and tends to increase with obesity in T2DM cases. Ins, case with insulinoma (text and Supplemental Table S1 at http:/ajp.amjpathol.org for details). implying intracellular formation. Moreover, we report the presence of toxic IAPP oligomers in association with disrupted mitochondrial membranes. Toxic IAPP oligomers have previously been shown to disrupt membranes causing nonselective channel activity followed by loss of membrane integrity in membrane bilayers. ${ }^{14}$ Also, toxic IAPP oligomers added to cells caused plasma membrane disruption, evaluated by electron microcopy noted to be comparable with that observed in the present stud-

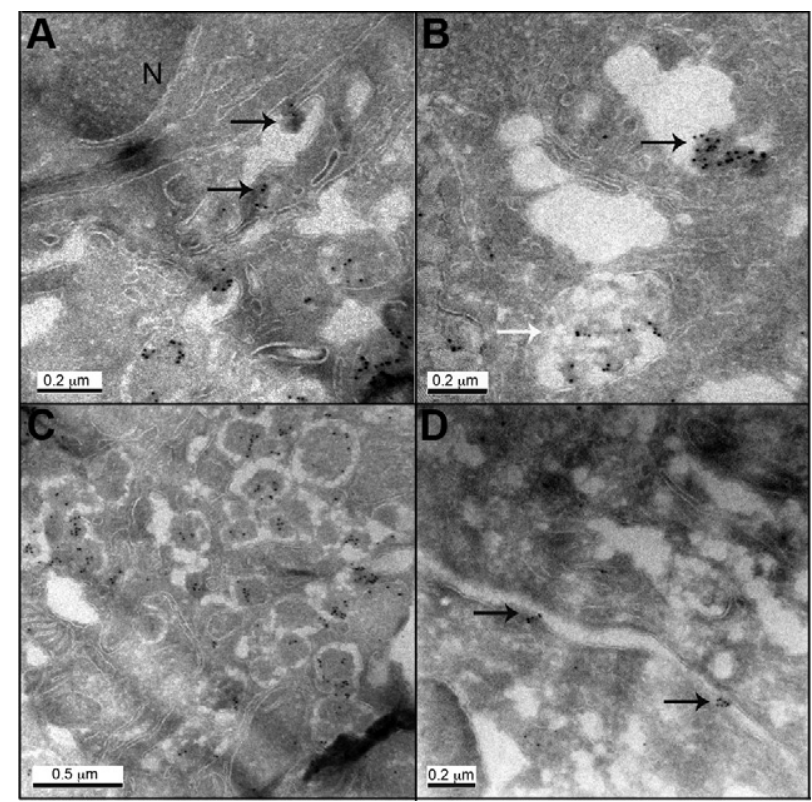

Figure 7. Electron micrographs of human $\beta$ cells from T2DM case (case \#3) labeled with A11 antibody (10 nm gold). A: Oligomer immunoreactivity was detected in perinuclear area in aggregates associated with ER (N - nucleus); B: in Golgi and abnormal diffuse aggregates in poorly defined structures (black and white arrows, respectively); C: in secretory vesicles, and $\mathbf{D}$ in association with plasma membrane. Arrows point to oligomer aggregates. Original magnification 1:60,000 (C), 1:80,000 (A, D), 1:100,000 (B). 
ies in association with toxic IAPP oligomers. ${ }^{7}$ This observation provides a novel mechanism for mitochondrial dysfunction in $\beta$ cells in T2DM, and potentially also in neurodegenerative diseases characterized by accumulation of misfolded protein oligomers.

There is increasing evidence that the toxic form of amyloidogenic proteins in neurodegenerative diseases is intracellular oligomers. ${ }^{15}$ The availability of antibodies that detect toxic oligomers has revealed a contribution of toxic oligomer formation in diseases such as heart failure, not previously recognized as a misfolded protein disease. ${ }^{16}$ We detected oligomer-immunoreactivity by light microscopy in islets from hIAPP transgenic mice, but not in mice overexpressing comparable levels of non amyloidogenic rodent IAPP or wild-type mice. ${ }^{11,12}$ Also, immunization against toxic oligomers did not protect these mice from developing diabetes, indirectly suggesting that toxic IAPP oligomers originate and act intracellularly. ${ }^{11}$ Here we used cryo-immunogold labeling to directly reveal that the toxic oligomers of IAPP form within the secretory pathway, escaping and disrupting cellular membranes including mitochondrial membranes.

The observation that toxic IAPP oligomers escape from the secretory pathway, presumably by disrupting membranes of ER, Golgi, and secretory vesicles, is consistent with in vitro studies noting that toxic oligomers of amyloidogenic proteins induce membrane permeability and membrane disruption. ${ }^{7,9}$ Indeed some data exist to suggest toxic oligomers may be formed within membranes. ${ }^{17}$ Induction of nonselective ion channels and/or disruption of membranes of the secretory pathway ${ }^{18}$ is also consistent with cytotoxicity mediated by increased cytosolic $\mathrm{Ca}^{2+}$ in neurodegenerative diseases. ${ }^{19}$ Moreover, evidence of hyperactivation of calpain has been observed in $\beta$ cells from people with T2DM.

A question that arises from these studies is, given the potentially catastrophic effects of the loss of subcellular compartmentalization of $\mathrm{Ca}^{2+}$ mediated by oligomer induced membrane leakage, why is cell death not more prominent, and the decline in cell mass not more rapid, in T2DM or neurodegenerative diseases? It is worth noting in this regard that only a subset of $\beta$ cells are positive for toxic oligomers in either transgenic hIAPP rodents or humans with T2DM. It is not known what underlies this heterogeneity. It may relate to different ages of cells since older cells are more vulnerable to accumulation of misfolded proteins. With aging, the mechanisms that protect against protein misfolding, such as availability of chaperones, decrease.$^{20}$ Likewise the mechanisms for removing misfolded proteins by the proteosome or autophagy decline with aging. ${ }^{21,22}$ Toxic IAPP oligomers were noted in human insulinoma cells that also expressed IAPP, even though the number of these transformed cells was obviously increasing and the cells sufficiently functional that the patients were identified by the resulting hypoglycemia. Tumor cells, including insulinoma cells, have high expression rates of anti-apoptotic factors such as BCL-2. ${ }^{23}$ BCL-2 is an attractive candidate to account for the relative protection of insulinoma cells from IAPP toxic oligomers as it has a known function in membrane repair. ${ }^{24}$ We also noted an increase in the frequency of cryo-immunogold labeling in the insulinoma cells, possibly implying increased degradation of misfolded proteins.

The present studies imply that toxic IAPP oligomers form intracellularly within the secretory pathway. It is likely they form in more than one compartment of the secretory pathway, and as such may be comprised of both prolAPP and IAPP, each of which may form oligomeric structures. ${ }^{25}$ Theoretically the ER is well defended from misfolding by the unfolded protein response, high concentrations of chaperon proteins, high $\mathrm{Ca}^{2+}$ concentration and oxidative environment. ${ }^{26}$ Mature insulin secretory vesicles should also be relatively protected from hIAPP aggregation with an acidic $\mathrm{pH}$ and high concentration of insulin, both known to inhibit IAPP aggregation. ${ }^{27}$ The IAPP aggregates observed adjacent to disrupted ER membrane (Figure 2 and 3 ) may have arisen in the ER or been misdirected back from disrupted secretory vesicles. The study of human tissue used here rather than transduced cell lines often used for study of protein misfolding has obvious advantages in therapeutic relevance, but also has limitations. One limitation is that it is not possible to directly establish either the site (or sites) or formation of toxic oligomers within the affected $\beta$ cells, or their itinerary thereafter.

A number of factors related to the formation of membrane-permeant oligomers might contribute to the dysfunction of the remaining pancreatic $\beta$ cells in T2DM and of neurons in neurodegenerative diseases. Calcium homeostasis and signaling not only is important for cell survival, but also underpins the intracellular trafficking and regulated discharge of secretory and synaptic vesicles at the cell membrane. ${ }^{28}$ Also, unregulated remodeling of the tubulin cytoskeleton consequent on hyperactivation of $\mathrm{Ca}^{2+}$-sensitive calpain might contribute to impaired intracellular vesicle trafficking. The delivery of toxic oligomers to the cell membrane might be expected to disrupt inter cell communication within islets. ${ }^{29}$ The disruption of mitochondrial membranes by proximate toxic oligomers escaped from the secretory pathway provides a novel mechanism for the well-recognized contribution of mitochondrial dysfunction to overall cellular dysfunction in both $\beta$ cells in T2DM ${ }^{30}$ and neurons in neurodegenerative diseases. ${ }^{31}$

An unresolved question in neurodegenerative diseases and T2DM is to what extent the formation of toxic oligomers is a consequence of the underlying disease process or a cause. This subject has been addressed in a recent review. ${ }^{3}$ In brief, it is increasingly clear that the extracellular amyloid that originally drew attention to the shared properties of these unfolded protein diseases plays a minimal role in cytotoxicity, while small toxic oligomers potentially play an important role. In transgenic models, as well as in transduced cells, cytotoxicity induced by amyloidogenic proteins has been shown to demonstrate a protein expression threshold effect that, when exceeded, leads to cytotoxicity and formation of toxic oligomers. ${ }^{32}$

This threshold can be crossed because of increased gene dosage (cross-breeding transgenic animals to homozygosity $)^{14}$ or increased expression of a fixed gene 
complement, for example by drug- or obesity-induced insulin resistance in the case of IAPP. ${ }^{33-35}$ Since IAPP expression increases with obesity, it is of interest to note that the percentage of $\beta$ cells positive for toxic oligomers increased much more steeply in T2DM. These data are consistent with the concept that the threshold for successful trafficking of IAPP might be decreased in T2DM, and contribute to the genetic predisposition to T2DM in the setting of insulin resistance. Consistent with the concept that in T2DM toxic IAPP oligomers develop intracellularly when expression of IAPP exceeds the capacity for that cell to traffic IAPP, the case of T2DM with insulinoma had minimal oligomer immunoreactivity in $\beta$ cells. However, there was immunoreactivity in the core of the islet amyloid deposits, raising the interesting possibility that this reflected cellular remnants of cells undergoing apoptosis before the onset of hypoglycemia. We postulate that amyloid subsequently developed from secreted IAPP that interacted with this oligomeric seed. This is consistent with the finding in homozygous hIAPP transgenic mice that toxic oligomers are found intracellularly when $\beta$ cell apoptosis is high, and precedes the development of extracellular islet amyloid. ${ }^{14}$

As well as mechanisms to prevent protein misfolding and aggregation, there are also systems in place to remove protein aggregates. Oligomer immunoreactivity in autophagosomes in human insulinoma, implies that autophagy may be important in removal of IAPP toxic oligomers. A recent elegant study has demonstrated that while soluble misfolded proteins are removed through the ERAD system; aggregated misfolded proteins are retained in ER and eliminated by the autophagy-lysosomal pathway independently from ERAD system. ${ }^{36}$ The detected increased toxic IAPP oligomers in T2DM may therefore be due to both increase oligomer formation, but also defective oligomer removal, for example through autophagy.

In summary, we report that IAPP toxic oligomers form within the secretory pathway in $\beta$ cells, to an increased extent in T2DM and as a function of obesity. Proteotoxicity due to toxic oligomers is increasingly appreciated as playing an important role in neurodegenerative diseases. Taking the present study along with the known properties of toxic IAPP oligomers to induce membrane damage, ${ }^{3}$ we conclude that toxic oligomers may contribute to the $\beta$ cell dysfunction and apoptosis characteristic of T2DM.

\section{Acknowledgments}

We thank Chang Liu and Ryan Galasso for their excellent technical support and Care Felix and Barbara Clerkin for assistance in procuring pancreas. We also thank Marianne Cilluffo, the Director of Microscopic Techniques and Electron Microscopy Core Facility at the Brain Research Institute at the University of California at Los Angeles.

\section{References}

1. Butler AE, Janson J, Bonner-Weir S, Ritzel R, Rizza RA, Butler PC: Beta-cell deficit and increased beta-cell apoptosis in humans with type 2 diabetes. Diabetes 2003, 52:102-110
2. Weyer C, Bogardus C, Mott DM, Pratley RE: The natural history of insulin secretory dysfunction and insulin resistance in the pathogenesis of type 2 diabetes mellitus. J Clin Invest 1999, 104:787-794

3. Haataja L, Gurlo T, Huang CJ, Butler PC: Islet amyloid in type 2 diabetes, and the toxic oligomer hypothesis. Endocr Rev 2008, 29:303-316

4. Ohsawa H, Kanatsuka A, Yamaguchi T, Makino H, Yoshida S: Islet amyloid polypeptide inhibits glucose-stimulated insulin secretion from isolated rat pancreatic islets. Biochem Biophys Res Commun 1989, 160:961-967

5. Butler PC, Chou J, Carter WB, Wang YN, Bu BH, Chang D, Chang JK, Rizza RA: Effects of meal ingestion on plasma amylin concentration in NIDDM and nondiabetic humans. Diabetes 1990, 39:752-756

6. Betsholtz C, Christmansson L, Engstrom U, Rorsman F, Svensson V, Johnson KH, Westermark P: Sequence divergence in a specific region of islet amyloid polypeptide (IAPP) explains differences in islet amyloid formation between species. FEBS Lett 1989, 251:261-264

7. Janson J, Ashley RH, Harrison D, McIntyre S, Butler PC: The mechanism of islet amyloid polypeptide toxicity is membrane disruption by intermediate-sized toxic amyloid particles. Diabetes 1999, 48:491-498

8. O'Brien TD, Butler AE, Roche PC, Johnson KH, Butler PC: Islet amyloid polypeptide in human insulinomas. Evidence for intracellular amyloidogenesis. Diabetes 1994, 43:329-336

9. Kayed R, Sokolov Y, Edmonds B, McIntire TM, Milton SC, Hall JE, Glabe CG: Permeabilization of lipid bilayers is a common conformation-dependent activity of soluble amyloid oligomers in protein misfolding diseases. J Biol Chem 2004, 279:46363-46366

10. Kayed R, Head E, Thompson JL, McIntire TM, Milton SC, Cotman CW, Glabe CG: Common structure of soluble amyloid oligomers implies common mechanism of pathogenesis. Science 2003, 300:486-489

11. Lin CY, Gurlo T, Kayed R, Butler AE, Haataja L, Glabe CG, Butler PC: Toxic human islet amyloid polypeptide (h-IAPP) oligomers are intracellular, and vaccination to induce anti-toxic oligomer antibodies does not prevent h-IAPP-induced beta-cell apoptosis in h-IAPP transgenic mice. Diabetes 2007, 56:1324-1332

12. Huang CJ, Haataja L, Gurlo T, Butler AE, Wu X, Soeller WC, Butler PC: Induction of endoplasmic reticulum stress-induced-cell apoptosis and accumulation of polyubiquitinated proteins by human islet amyloid polypeptide. Am J Physiol Endocrinol Metab 2007, 293:E1656-E1662

13. Ryazantsev S, Yu WH, Zhao HZ, Neufeld EF, Ohmi K: Lysosomal accumulation of SCMAS (subunit c of mitochondrial ATP synthase) in neurons of the mouse model of mucopolysaccharidosis III B. Mol Genet Metab 2007, 90:393-401

14. Janson J, Soeller WC, Roche PC, Nelson RT, Torchia AJ, Kreutter DK, Butler PC: Spontaneous diabetes mellitus in transgenic mice expressing human islet amyloid polypeptide. Proc Natl Acad Sci USA 1996, 93:7283-7288

15. Walsh DM, Klyubin I, Fadeeva JV, Cullen WK, Anwyl R, Wolfe MS, Rowan MJ, Selkoe DJ: Naturally secreted oligomers of amyloid beta protein potently inhibit hippocampal long-term potentiation in vivo. Nature 2002, 416:535-539

16. Sanbe A, Osinska H, Saffitz JE, Glabe CG, Kayed R, Maloyan A, Robbins J: Desmin-related cardiomyopathy in transgenic mice: a cardiac amyloidosis. Proc Natl Acad Sci USA 2004, 101:10132-10136

17. Jayasinghe SA, Langen R: Membrane interaction of islet amyloid polypeptide. Biochim Biophys Acta 2007, 1768:2002-2009

18. Mitchell KJ, Pinton P, Varadi A, Tacchetti C, Ainscow EK, Pozzan T, Rizzuto R, Rutter GA: Dense core secretory vesicles revealed as a dynamic $\mathrm{Ca}(2+)$ store in neuroendocrine cells with a vesicle-associated membrane protein aequorin chimaera. J Cell Biol 2001, 155:41-51

19. Vosler PS, Brennan CS, Chen J: Calpain-mediated signaling mechanisms in neuronal injury and neurodegeneration. Mol Neurobiol 2008, 38:78-100

20. Morimoto RI: Proteotoxic stress and inducible chaperone networks in neurodegenerative disease and aging. Genes Dev 2008, 22:1427-1438

21. Morimoto RI, Cuervo AM: Protein homeostasis and aging: taking care of proteins from the cradle to the grave. J Gerontol A Biol Sci Med Sci 2009, 64:167-170

22. Kaushik S, Kiffin R, Cuervo AM: Chaperone-mediated autophagy and aging: a novel regulatory role of lipids revealed. Autophagy 2007, 3:387-389 
23. Iwahashi $\mathrm{H}$, Hanafusa $\mathrm{T}$, Eguchi $\mathrm{Y}$, Nakajima $\mathrm{H}$, Miyagawa J, Itoh $\mathrm{N}$, Tomita K, Namba M, Kuwajima M, Noguchi T, Tsujimoto Y, Matsuzawa Y: Cytokine-induced apoptotic cell death in a mouse pancreatic betacell line: inhibition by Bcl-2. Diabetologia 1996, 39:530-536

24. Tsujimoto Y: Cell death regulation by the Bcl-2 protein family in the mitochondria. J Cell Physiol 2003, 195:158-167

25. Jha S, Sellin D, Seidel R, Winter R: Amyloidogenic propensities and conformational properties of ProlAPP and IAPP in the presence of lipid bilayer membranes. J Mol Biol 2009, 389:907-920

26. Scheuner D, Kaufman RJ: The unfolded protein response: a pathway that links insulin demand with beta-cell failure and diabetes. Endocr Rev 2008, 29:317-333

27. Kudva YC, Mueske C, Butler PC, Eberhardt NL: A novel assay in vitro of human islet amyloid polypeptide amyloidogenesis and effects of insulin secretory vesicle peptides on amyloid formation. Biochem $J$ 1998, 331:809-813

28. Levitan ES: Signaling for vesicle mobilization and synaptic plasticity. Mol Neurobiol 2008, 37:39-43

29. Ritzel RA, Meier JJ, Lin CY, Veldhuis JD, Butler PC: Human islet amyloid polypeptide oligomers disrupt cell coupling, induce apoptosis, and impair insulin secretion in isolated human islets. Diabetes 2007, 56:65-71

30. Maechler $\mathrm{P}$, Wollheim CB: Mitochondrial function in normal and diabetic beta-cells. Nature 2001, 414:807-812
31. Gibson GE, Karuppagounder SS, Shi Q: Oxidant-induced changes in mitochondria and calcium dynamics in the pathophysiology of Alzheimer's disease. Ann NY Acad Sci 2008, 1147:221-232

32. Matveyenko AV, Butler PC: Islet amyloid polypeptide (IAPP) transgenic rodents as models for type 2 diabetes. Ilar J 2006, 47:225-233

33. Couce M, Kane LA, O'Brien TD, Charlesworth J, Soeller W, McNeish J, Kreutter D, Roche P, Butler PC: Treatment with growth hormone and dexamethasone in mice transgenic for human islet amyloid polypeptide causes islet amyloidosis and beta-cell dysfunction. Diabetes 1996, 45:1094-1101

34. Soeller WC, Janson J, Hart SE, Parker JC, Carty MD, Stevenson RW, Kreutter DK, Butler PC: Islet amyloid-associated diabetes in obese $\mathrm{A}(\mathrm{vy}) / \mathrm{a}$ mice expressing human islet amyloid polypeptide. Diabetes 1998, 47:743-750

35. Hoppener JW, Oosterwijk C, Nieuwenhuis MG, Posthuma G, Thijssen $\mathrm{JH}$, Vroom TM, Ahren B, Lips CJ: Extensive islet amyloid formation is induced by development of Type II diabetes mellitus and contributes to its progression: pathogenesis of diabetes in a mouse model. Diabetologia 1999, 42:427-434

36. Ishida Y, Yamamoto A, Kitamura A, Lamande SR, Yoshimori T, Bateman $\mathrm{JF}$, Kubota H, Nagata K: Autophagic elimination of misfolded procollagen aggregates in the endoplasmic reticulum as a means of cell protection. Mol Biol Cell 2009, 20:2744-2754 